\title{
EL MOBILIARIO Y LOS BIENES MUEBLES DE UNA CASONA SEÑORIAL DURANTE EL ANTIGUO RÉGIMEN EN EL NORTE DE ESPAÑA \\ MOVABLE PROPERTY AND FURNITURE OF AN ARISTOCRATIC HOUSE IN THE OLD REGIME IN THE NORTH OF SPAIN
}

Ana Isabel García López* Universidad de Oviedo

\section{Resumen}

El mobiliario y objetos de uso cotidiano que una familia, de una época y contexto determinado, va adquiriendo con el paso de los años convierten su vivienda en un hogar. Los muebles, enseres, ropa, herramientas, objetos decorativos... facilitan el día a día de sus miembros y reflejan su estilo de vida. Por ello debemos entender la vivienda no sólo como un conjunto de paredes que dan cobijo a una familia, sino como "un reflejo de dicho individuo, miembro de una sociedad, que piensa y siente de una u otra forma en una época determinada y dentro de un contexto histórico económico concreto" ${ }^{1}$. El caso concreto que analizaremos es el del mobiliario y bienes muebles de la Casona de El Cotero, localizada en Peñamellera Baja, de los que tenemos constancia a través de los documentos familiares, que pueden ser reflejo de otras casas pertenecientes a la hidalguía del norte de España del Antiguo Régimen. España.

Palabras clave: mobiliario, bienes muebles, documentos, hidalguía,

\section{Abstract}

Furniture and everyday objects that a family, of a time and a given context, is acquiring through the years turn the house into a home. Furniture, goods, tools, decorative objects... facilitate the everyday life of this members and reflect their lifestyle. That's why we should understand home not only as a set of walls which provide shelter for a family, but as "a reflection of said individual, member of a society, who thinks and feels one way another given season and given historical economical context". The case we will analyze is about the furniture and movables of the "Casona de El Cotero", placed on Peñamellera Baja, of which we are aware through family records, which may be reflection of the other belonging to the north of Spain nobility from the Old Regime.

Keywords: movable property, furniture, documents, nobility, Spain.

\footnotetext{
*E-mail: anaovds83@hotmail.com
} 


\section{Introducción}

Es muy difícil, por no decir imposible, en la mayoría de los casos llegar a conocer en profundidad el mobiliario y demás objetos utilizados en el día a día por los habitantes de las casonas y palacios que se distribuyen de forma abundante por todo el territorio norte. Dichas construcciones fueron promovidas durante la Edad Moderna por la nobleza y la hidalguía pudiente, dotándolas posteriormente con estos bienes que son objeto de nuestro estudio. De esta manera la vivienda llegó a ser "una forma de representación de la familia, de su condición social, de su posición en la jerarquía estamental, convirtiéndola en una de las señas de identidad del linaje familiar"2.

En las siguientes líneas analizaremos la evolución de los bienes muebles y demás objetos utilizados en el día a día en la Casona de El Cotero, fundada en el Siglo XVII por Toribio González de Serdio y que pasaría a manos de la familia Guerra Mier en el Siglo XVIII. Será entonces, gracias al estudio de diversos documentos conservados en su mayoría en el archivo de la familia, tales como inventarios y particiones de bienes, que podremos hacernos una idea bastante fiel de cómo pudieron ser estos bienes y llevar a cabo una recreación del interior doméstico de la casona y de la vida de sus habitantes; porque si bien el mueble desde su origen surgió con una funcionalidad clara, la de hacer más cómoda la vida, también pone de manifiesto el estatus y la representación social ${ }^{3}$.

\section{La Casona de El Cotero, un ejemplo de arquitectura nobiliaria.}

En la Edad Moderna en el norte de España se asiste a un despunte en la construcción de casonas y palacios rurales encargados por las familias más destacadas de cada región, pertenecientes a la élite nobiliaria y aristocrática local. En estos momentos un elevado porcentaje de la población de la zona norte era hidalga pero, a pesar de ello, la mayor parte no contaba con recursos suficientes aunque, como estamento más bajo de la nobleza, no tuvieran que hacer frente a impuestos. Además nos encontramos en la zona más oriental de Asturias, que en aquellos momentos pertenecía a la Provincia de Santander, una de las más pobres de la región, cuya base de riqueza se basaba en las propiedades rústicas. De esta manera, sólo algunas familias pudientes eran capaces de afrontar una construcción de estas características como símbolo de poder y estatus y que conllevaba además su posterior mantenimiento.

Ejemplo de esa arquitectura de carácter señorial y residencia de un mayorazgo es la Casona de El Cotero, también conocida como Casona de los Guerra, localizada en el pueblo de Buelles (Fig. 1). Aunque en origen no perteneció a esta familia, ya fue erigida en el siglo XVII por esa aristocracia local y posteriormente ampliada en los siglos XVIII y XIX por la familia Guerra Mier ${ }^{4}$, descendientes de un importante linaje de hidalgos de la zona de las Peñamelleras que despuntó como familia de grandes terratenientes. El origen de la casona se remonta al siglo XVII cuando la funda Toribio González de Serdio, cura de Buelles y Narganes ${ }^{5}$, contribuyendo a ello Pedro Fernández de Serdio ${ }^{6}$, cura del 
mismo lugar. Posteriormente heredarían la casona Alonso Fernández de Serdio y Escandón y María González de Serdio y Noriega, hija de Don Toribio7. Que en la fachada principal se localicen los escudos de las familias Noriega y Escandón nos lleva a pensar que este matrimonio pudo hacer una obra importante ya en la casona ${ }^{8}$. El heredero del mayorazgo fue su primogénito Francisco Fernández de Serdio y a éste le sucedió su hijo Pedro Enrique Fernández de Serdio. Sucedió como heredera a Pedro Enrique su hija $\mathrm{M}^{\mathrm{a}}$ Antonia, algo que no era común, ya que las mujeres no solían heredar si había un descendiente varón; así que estaríamos ante un caso de mayorazgo regular, donde suceden los hijos varones, y en caso de no haberlo, las hijas dentro de cada línea ${ }^{9}$. $\mathrm{M}^{\mathrm{a}}$ Antonia Fernández de Serdio contrajo matrimonio en 1727 con Joseph Narciso Ignacio Guerra de Mier, que por entonces residía en Mier (Peñamellera Alta), y ambos se instalaron en la Casona de El Cotero quedando unidos los mayorazgos de las dos familias.

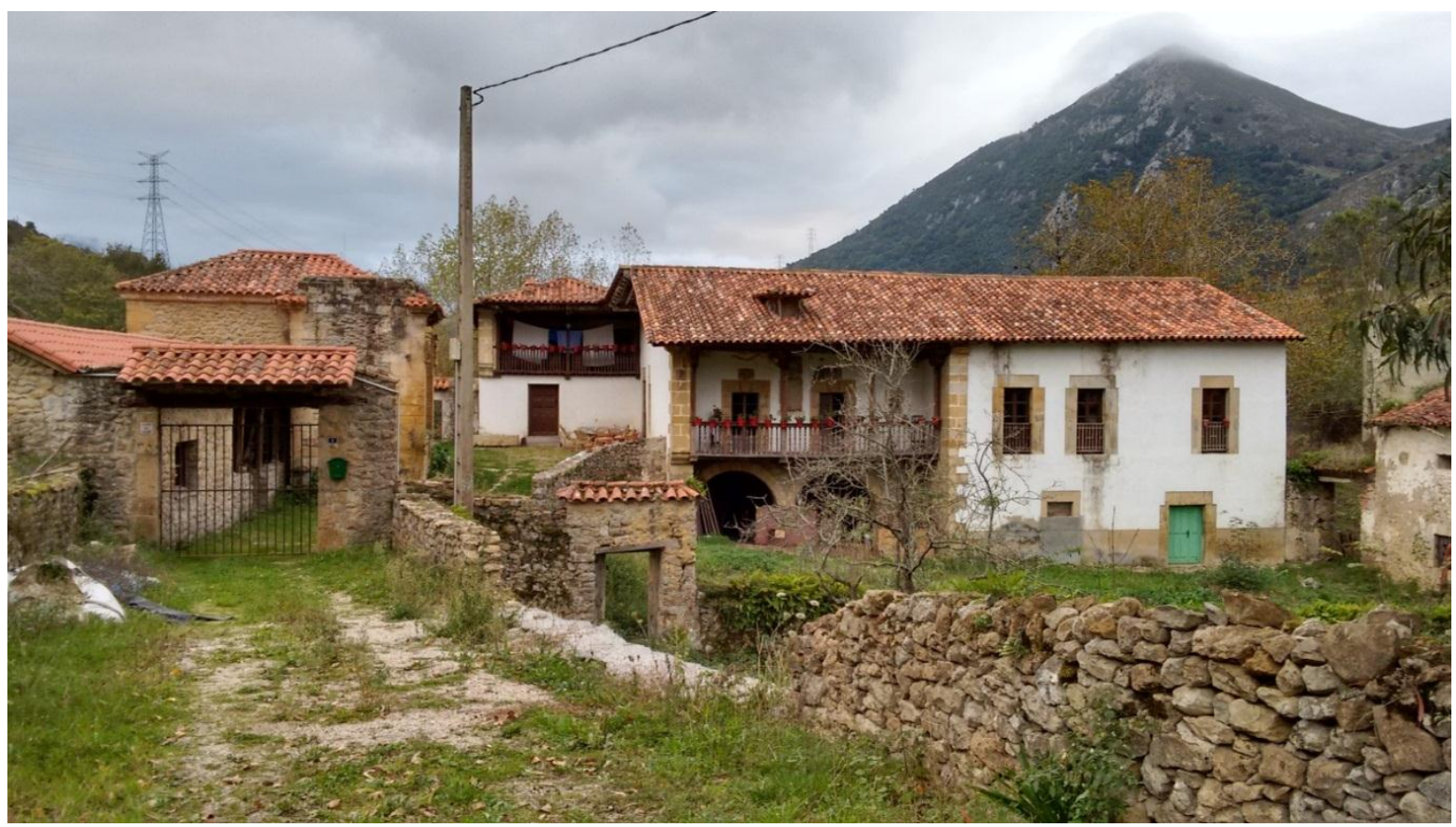

Fig. 1. Casona El Cotero. Buelles, siglo XVII.

Joseph Narciso ejerció el oficio de escribano y posteriormente el de Administrador de la Rentas del Tabaco y de Rentas Reales en la Caja de Administración de San Vicente de la Barquera ${ }^{10}$ y fue uno de los mayores hacendados de Peñamellera Baja11. También él llegó adinerado al matrimonio al recibir las herencias de su padre y de su tío ${ }^{12}$, de la que menciona que de ella aportó al matrimonio siete mil reales en dinero físico. En 1749, según el inventario del Catastro de Ensenada de ese año, el concejo formado por Buelles, El Mazo y Narganes, contaba con 90 vecinos y 250 casas, de las cuales 100 eran de vivienda ${ }^{13}$. En Buelles la familia tenía más de sesenta propiedades pero además, también las tenía en diversos pueblos de los concejos de Peñamellera Baja, Val de San Vicente y Rivadedeva, entre los que se contaban casas, casares, capillas, heredades labrantías, prados en régimen de aparcería y $\operatorname{molinos}^{14}$. No 
sólo vivían del sueldo que proporcionaba el trabajo de Joseph Narciso, sino que también disponían de las rentas que les reportaban los contratos de aparcería de sus tierras.

Hacia 1770 la casona sufrió un incendio, originado probablemente en el hogar, y que pudo haber destruido algo de mobiliario. Por esta razón se llevó a cabo una ampliación con la construcción de la cocina (Fig. 2) y al mismo tiempo se edificó la capilla ${ }^{15}$, que cuenta con una inscripción de haber sido construida en 1771. Es curioso que erigiera esta familia otra capilla cuando ya poseía el patronato de la Capilla de Santo Toribio en la iglesia del Buelles, además de la de San Juan de Prío y parte del patronato en las iglesias de San Juan de Rivadedeva, Santa María de Colombres y Santa Eulalia de Carranzo ${ }^{16}$. Podría tratarse de esta manera de "un mecanismo de acercamiento a las mansiones de lujo más nobles"17.

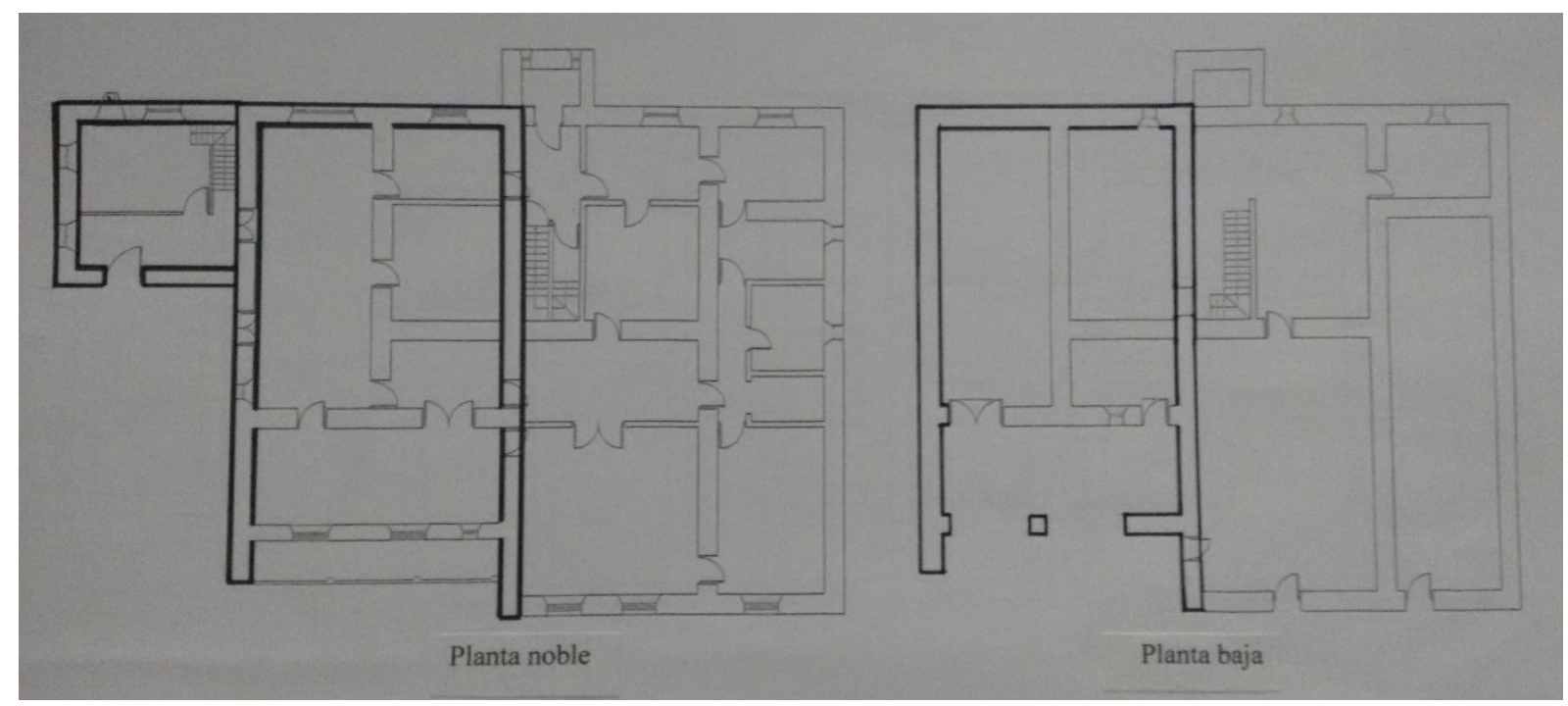

Fig. 2. Plano de ampliación tras el incendio.

Joseph Narciso falleció en el año 1785 sucediéndole como heredero su hijo Joseph Antonio que, entre 1785 y 1799, tuvo que hacer frente a un pleito contra sus hermanos a causa del inventario de bienes de la herencia familiar ${ }^{18}$. Sería posteriormente Pedro Antonio ${ }^{19}$, hijo de Joseph Antonio y heredero del mayorazgo, el que ampliaría nuevamente la casona construyendo el bloque derecho con anterioridad a 1864. Su único hijo y heredero fue Agapito Guerra Mier y Torre ${ }^{20}$, que tuvo cinco hijos, y a éste le sucedió su primogénito Juan pero, que tras fallecer en 1926, fue su hermano Pedro, que en estas fechas se encontraba en Puebla de México como administrador de varias haciendas de caña de azúcar, el que tendría que hacerse cargo de la herencia ${ }^{21}$. 


\section{El mobiliario y demás bienes muebles de la casona de El Cotero a través de las fuentes documentales.}

El mobiliario y ajuar doméstico contenido en el interior de una vivienda son en conjunto "testigos de las personas y las sociedades por las que fueron creados y donde perduraron" 22 , pero la mayor parte de los muebles y objetos de uso cotidiano no han llegado hasta nuestros días. En parte esto es debido al desgaste ocasionado por el uso y el paso del tiempo, hasta el punto de que sus dueños consideran que ya no son útiles y los desechan o trasladan a otras casas más humildes y son sustituidos por otros más modernos. Por otro lado, los muebles que con suerte han sobrevivido, algunos se han conservado en la casa de origen y otros se han vendido por diferentes motivos y se les pierde la pista definitivamente. Por ello son los inventarios, testamentos y otros documentos similares las fuentes de información más relevantes que debemos analizar para hacer una posterior interpretación de los bienes. De esta forma se puede llegar a obtener una imagen certera del estilo de vida, usos y costumbres de los habitantes de estas casonas, la relación entre familiares, además de su capacidad económica y las modas y gustos que regían en la época. Esto es gracias a que en numerosas ocasiones al inventariar los bienes se detallaban sus características (peso, medida, color, hechura...) e incluso se procedía muchas veces a su tasación, llevada a cabo por "contadores y tasadores, nombrados de oficio entre "especialistas" gremiales, maestros de la madera, plata, roperos y labradores, o simplemente vecinos (...) en el mismo momento en que se pasaba revista a los enseres o inmediatamente después" 23 . Además, resulta imprescindible realizar el análisis y estudio con cierta precaución en el momento de identificar los objetos ya que los nombres de la época pueden no coincidir con los que son usados en la actualidad, lo que podría ser motivo de confusión. También es necesario tener en cuenta que no siempre se procedía a la práctica de los inventarios post-mortem, ya que estos eran realizados por escribanos y su encargo conllevaba un cierto desembolso monetario; al no contar todo el mundo en aquella época con los recursos necesarios, muchas veces sólo se efectuaban cuando podía producirse un litigio entre los herederos, en cuyo caso se podría pensar que tal vez hubiera cierta ocultación de información relativa a los bienes escriturados llevados a cabo por alguna de las partes ${ }^{24}$. Tal es el caso del pleito que mantuvieron durante años los herederos de Joseph Narciso ${ }^{25}$.

La casona estuvo en situación de casi abandono durante varias décadas, después fue puesta en venta y finalmente la familia decidió quedarse con ella y comenzar unas obras de rehabilitación para que no acabara en ruinas. El problema es que en ese periodo de tiempo se vendieron algunos de los ya de por sí pocos muebles que aún se conservaban. De ahí que el único apoyo que tengamos para su estudio sean estos inventarios conservados entre los documentos familiares.

El archivo de los Guerra está formado por varios documentos de diferentes épocas: del siglo XVIII, del XIX y del XX, aunque algunos son copias posteriores del documento original. Nos centraremos principalmente en un inventario de 1785, realizado tras la muerte de Joseph Narciso que se refiere a los bienes que 
se encontraban en la casona entre otros, sin hacer distinción entre vinculados y libres, y de manera secundaria en otros dos, uno de 1797 en el cual el mobiliario al que se refiere pertenece a los bienes libres y otro de 1831, este último con los bienes tasados, pero que se centra en los bienes libres que son partibles entre los herederos. Finalmente, haremos alguna referencia a otros posteriores en los que se mencione algún mueble que pudiera pertenecer a esta época y que aumenten la información disponible.

Gracias a ese inventario de 1785 sabemos que, en esta época, la casa contaba con distintas estancias bien diferenciadas: la cocina, la sala inmediata a la cocina, la sala inmediata al balcón principal del lado de saliente, la sala inmediata al lado norte y el cuarto trasero hacia el cotero. No queda claro la función a la que estaban destinadas concretamente cada una, a excepción de la cocina, pero en todo caso las habitaciones estaban separadas y con toda probabilidad tabicadas, algo todavía no muy común en estos momentos ya que "la falta de privacidad doméstica en la distribución de los espacios habitados interiores continuaba en la segunda mitad del siglo XVIII. Sólo entre los sectores privilegiados, y no siempre, las habitaciones asumían lentamente funciones específicas" 26 . Es en los tratados franceses donde surge la especialización de las estancias en la segunda mitad del siglo XVIII de acuerdo a los cambios sociales que tienen lugar en este momento ${ }^{27}$. Aunque la casona no llega a tener la envergadura de un gran palacio, tampoco se trata de una simple casa de campesinos que apenas solía tener una cocina y uno o dos cuartos. Sin embargo, nos muestra que sus propietarios, como terratenientes de la zona y dueños de numerosas propiedades, gozaban de una economía saneada disponiendo así de gran cantidad de muebles (camas, armarios, mesas, bancos...), aunque aún a finales el siglo XVIII, según Máximo García Fernández, no había un mobiliario amplio ni con usos claramente definidos (excepto la cama ordinaria) y tampoco había piezas excesivamente novedosas que implicaran claras mejoras en la organización de estos espacios ${ }^{28}$.

Podemos poner en relación el mobiliario que había en una casa campesina en el siglo XVIII en Asturias ${ }^{29}$ con el mobiliario de esta casona en 1785.

\begin{tabular}{|l|l|l|l|}
\hline \multicolumn{2}{|l|}{$\begin{array}{l}\text { Casa campesina asturiana siglo } \\
\text { XVIII }\end{array}$} & \multicolumn{2}{l|}{ Casona de El Cotero 1785} \\
\hline \multirow{4}{*}{ Cocina } & $\begin{array}{l}\text { escaño } \\
\text { escabeles } \\
1 \text { o varias arcas } \\
\text { pequeñas } \\
1 \text { masera }\end{array}$ & Cocina & $\begin{array}{l}3 \text { escaños } \\
1 \text { herrada } \\
1 \text { masera } \\
1 \text { silla }\end{array}$ \\
& & Sala inmediata a la & $\begin{array}{l}5 \text { barcas } \\
1 \text { bufete } \\
2 \text { armarios o cajones } \\
\text { altos }\end{array}$ \\
\hline
\end{tabular}




\begin{tabular}{|c|c|c|c|}
\hline & & $\begin{array}{l}\text { Sala inmediata al } \\
\text { balcón principal del } \\
\text { lado de saliente }\end{array}$ & $\begin{array}{l}1 \text { bufete } \\
2 \text { bancos de respaldo } \\
1 \text { mesa rasa } \\
2 \text { arquillas }\end{array}$ \\
\hline & & $\begin{array}{l}\text { Sala inmediata al } \\
\text { lado norte }\end{array}$ & $\begin{array}{l}3 \text { mesas } \\
2 \text { mesitas } \\
4 \text { bancos de respaldo } \\
14 \text { taburetes } \\
1 \text { silla } \\
2 \text { armarios }\end{array}$ \\
\hline & & $\begin{array}{l}\text { Cuarto trasero hacia } \\
\text { el cotero }\end{array}$ & $\begin{array}{l}3 \text { taburetes } \\
1 \text { cajonato } \\
1 \text { arquilla }\end{array}$ \\
\hline & & $\begin{array}{l}\text { Diferentes salas y } \\
\text { cuartos }\end{array}$ & 12 lechos de camas \\
\hline
\end{tabular}

Cuadro comparativo entre una casa campesina asturiana del siglo XVIII y la Casona de El Cotero

Observamos que hay una clara diferencia entre ambas no sólo en cuanto a cantidad, sino también en cuanto a variedad de tipologías. Podemos observar mejor esa variedad a través del siguiente cuadro ${ }^{30}$ :

\begin{tabular}{|c|c|c|c|}
\hline TIPOLOGÍA & MUEBLE & NÚMERO EN 1785 & NÚMERO ${ }^{31}$ EN 1797 \\
\hline \multirow{6}{*}{$\begin{array}{l}\text { MUEBLES } \\
\text { DE } \\
\text { GUARDAR }\end{array}$} & arca & 8 & - \\
\hline & armario/cajón & 4 & 2 \\
\hline & cajonato & 1 & - \\
\hline & baúl & - & 1 \\
\hline & escritorio & - & 1 \\
\hline & total & 13 & 4 \\
\hline \multirow{5}{*}{$\begin{array}{l}\text { MUEBLES } \\
\text { DE ASIENTO }\end{array}$} & escaños & 3 & 3 \\
\hline & sillas & 2 & 1 \\
\hline & banco de respaldo & 8 & 8 \\
\hline & taburete & 17 & - \\
\hline & total & 30 & 12 \\
\hline \multirow{3}{*}{$\begin{array}{l}\text { MUEBLES } \\
\text { DE APOYO }\end{array}$} & mesa & 6 & 5 \\
\hline & bufete & 2 & - \\
\hline & total & 8 & 5 \\
\hline CAMAS & camas & 12 & 12 \\
\hline \multicolumn{2}{|c|}{ Total todos los muebles } & 63 & 33 \\
\hline
\end{tabular}

Tipologías mobiliarias de la Casona de El Cotero 
Como podemos observar abundan las arcas, principal mueble de guardar, en varios tamaños y destinadas a guardar ropa, papeles y el ajuar y la plata ${ }^{32}$. Aunque en el inventario de 1785 no se especifica que estuvieran decoradas lo lógico es pensar que por lo menos la mayor parte de ellas sí lo estuvieran, ya que normalmente las que no lo estaban se utilizaban para guardar grano o legumbres fuera de la casa. Es más, en el inventario de 1831 se especifica que dos arcas eran de nogal con molduras, madera muy noble usada en estos muebles, y un arca que también presentaba molduras, tasadas en 55, 65 y 47 reales respectivamente ${ }^{33}$. Debemos tener en cuenta que la vida media efectiva de las arcas entre 1785-1800 era de unos 58 años ${ }^{34}$, razón por la cual, podemos pensar que se tratarían de algunas de las que había en 1785 . Actualmente se conserva un arca de mediano tamaño que dataría del siglo XVIII pero que no presenta ninguna talla decorativa, aunque las bisagras serían añadidos posteriores (Fig. 3).

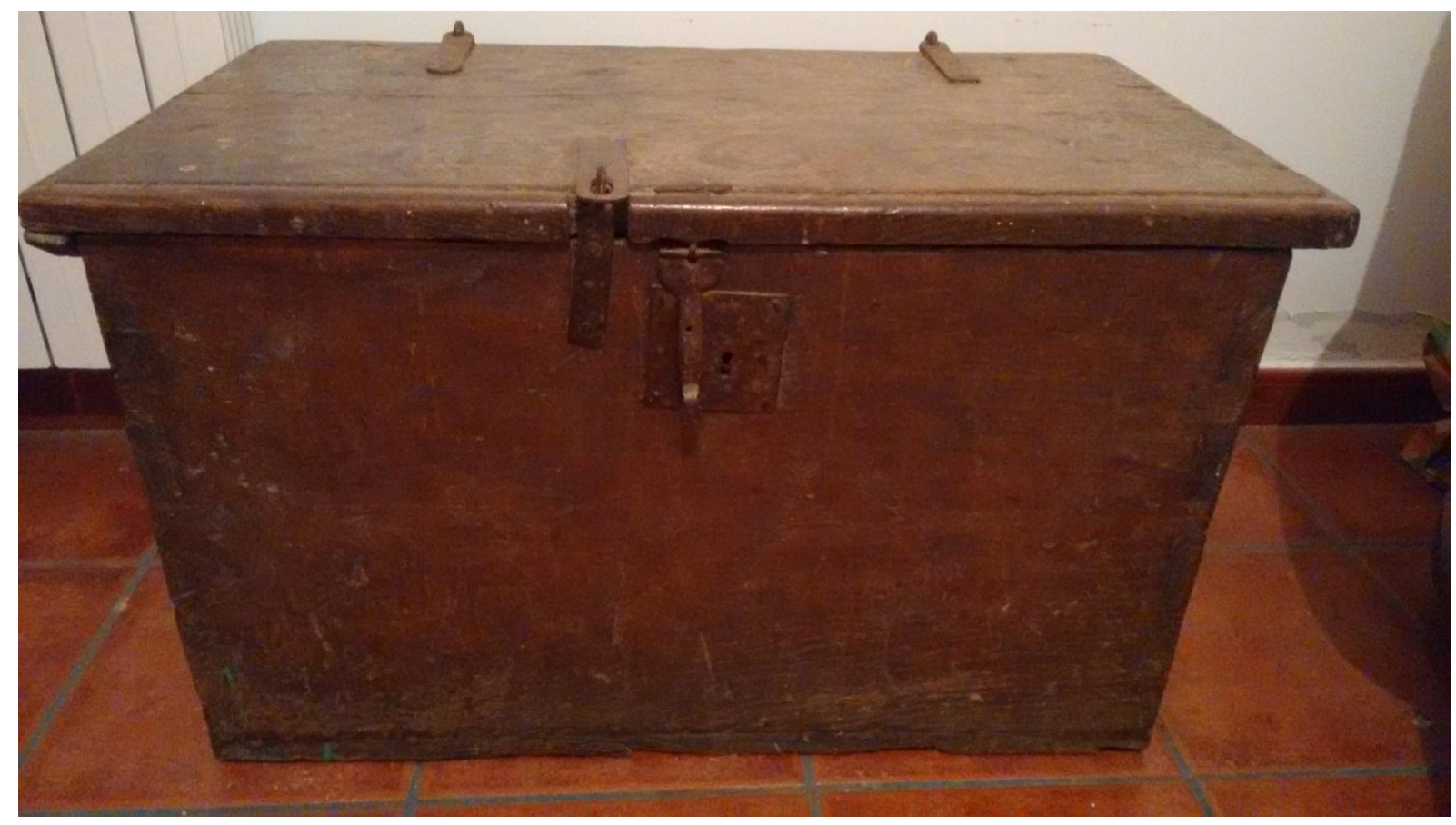

Fig. 3. Arca del siglo XVIII que aún se conserva.

Otro mueble de guardar que resulta interesante es el armario que, según Gerardo Díaz Quirós, se incorpora tardíamente al mobiliario asturiano, pero que podría haberse anotado en los inventarios como "cajón"35. Curiosamente el inventario de 1785 confirma que en aquella época había cuatro, de los que se dice que dos de ellos eran "armarios o cajones altos de madera lisos viejos que sirven de dispensa" 36 lo que ciertamente demuestra que podían ser denominados de ambas maneras. Además, estos se describen como viejos ${ }^{37}$ por lo que podrían tratarse de armarios de principios del siglo XVIII o incluso del siglo XVII. Los otros dos armarios se usaban para guardar ropa. Parece ser que contar con cuatro armarios en esta época no sería lo habitual ya que según un estudio de $\mathrm{M}^{\mathrm{a}}$ Eugenia Escudero Sánchez ${ }^{38}$ que analiza cuarenta inventarios post-mortem, 
realizados entre 1662 y 1782 pertenecientes a familias de San Vicente de la Barquera, solamente en tres de ellos de la segunda mitad del siglo XVIII se mencionan armarios. Tampoco aparecen armarios en los 101 inventarios de la zona rural de Palencia de entre 1785-1800 que estudia Fernando Ramos Palencia ${ }^{39}$.

El último mueble de esta tipología al que haremos referencia y que está presente en el inventario de 1797 es el escritorio, el cual también puede ser designado como estrado, contador, papelera o arquimesa ${ }^{40}$. El escritorio era utilizado por los señores de la casa para custodiar sus papeles, como en este caso en el que se guardaba el oficio y los documentos de Joseph Narciso ${ }^{41}$, y que ya podría haberse inventariado en 1785 como un "cajonatto" en el que hallaron diversos papeles ${ }^{42}$. Es más, si se tiene en cuenta que la vida útil de estos muebles en esa época rondaba los 58 años ${ }^{43}$, aunque podían alargar su uso mucho más y que pudo haberse adquirido tras el incendio, podríamos considerar que se trataba también de la papelera que se cita en un inventario de 1864 y que fue tasada por entonces en ciento sesenta reales ${ }^{44}$, un precio que puede considerarse elevado y que denotaría la calidad del mueble.

Los muebles de asiento también presentaban varias tipologías, aunque los más comunes eran los escaños y los bancos. En 1785 los tres escaños que había en la cocina eran de madera con el respaldo y rejillas torneadas ${ }^{45}$ y serán los mismos que había en 1797 descritos como bastante usados y de nogal y castaño ${ }^{46}$. Se trataría de muebles de calidad, tanto por el tipo de madera usado como por el hecho de que estaban torneados. Los escaños de la cocina se diferenciarían de los demás bancos de la casa en que estos, además de tener un asiento más ancho, presentarían una tabla colocada sobre el respaldo que se abatiría para hacer las veces de mesa, permitiendo comer a varios miembros de la familia a la vez sobre ella. Se mencionan dos sillas en 1785, una con molduras en el respaldo y otra "con el piso de Abanillas" 47 , lo que nos hace pensar que habría sido adquirida en esta localidad perteneciente al concejo de Val de San Vicente. También hay referencias al taburete ${ }^{48}$, una especie de silla sin respaldo poco corriente en épocas tempranas. En 1785 ya había diecisiete, catorce de ellos estaban en una misma sala, por lo que si tenemos en cuenta que en la misma se hallaban varias mesas y bancos, podemos suponer que la estancia haría las veces de comedor y que tal cantidad de taburetes vendría determinado por el número de comensales. El número de bancos también era elevado, en concreto ocho. Se conserva el respaldo de un banco que, aunque originariamente estaba en la capilla de Santo Toribio, fue trasladado a la casona en el siglo $\mathrm{XX}^{49}$ y merece especial atención por la talla que presenta (Fig. 4). Los bancos que había en las iglesias "reservados a las grandes familias que disfrutaban de privilegios en las cercanías del altar muestran a través de su decoración, habitualmente un blasón tallado o pintado, la riqueza de sus comitentes" 50 . Tal es este el caso, en el que el respaldo, de grandes dimensiones $\left(2^{\prime} 62 \times 0^{\prime} 34 \mathrm{~m}\right)$, se presenta dividido en cinco paneles decorados mediante diversos relieves y una inscripción que versa de la siguiente manera: "DEL ORIGEN DE TOLEDO EL MUI NOBLE CABALLERO QUANDO BINIERON LOS MOROS PELEO COMO BARON Y EN TIEMPO DE LOS GODOS DON PEDRO DIAZ TELEMON HUYENDO BINO A ESCANDON 
DEFENDIENDOSE DE TODOS"51 (Fig. 5). Podríamos datar con toda seguridad este banco en el siglo XVII, y sería encargado por la familia Fernández de Serdio, que había fabricado y dotado la capilla ${ }^{52}$. Debemos recordar que estos llevaban el apellido Escandón, de renombre en esa zona, y encargarían este banco en el que tallaron su emblema ${ }^{53}$ en el panel central (Fig. 6), como muestra de su estatus social y económico y ostentación de su linaje, en una época en el que las iglesias aún no tenían asientos para los fieles.

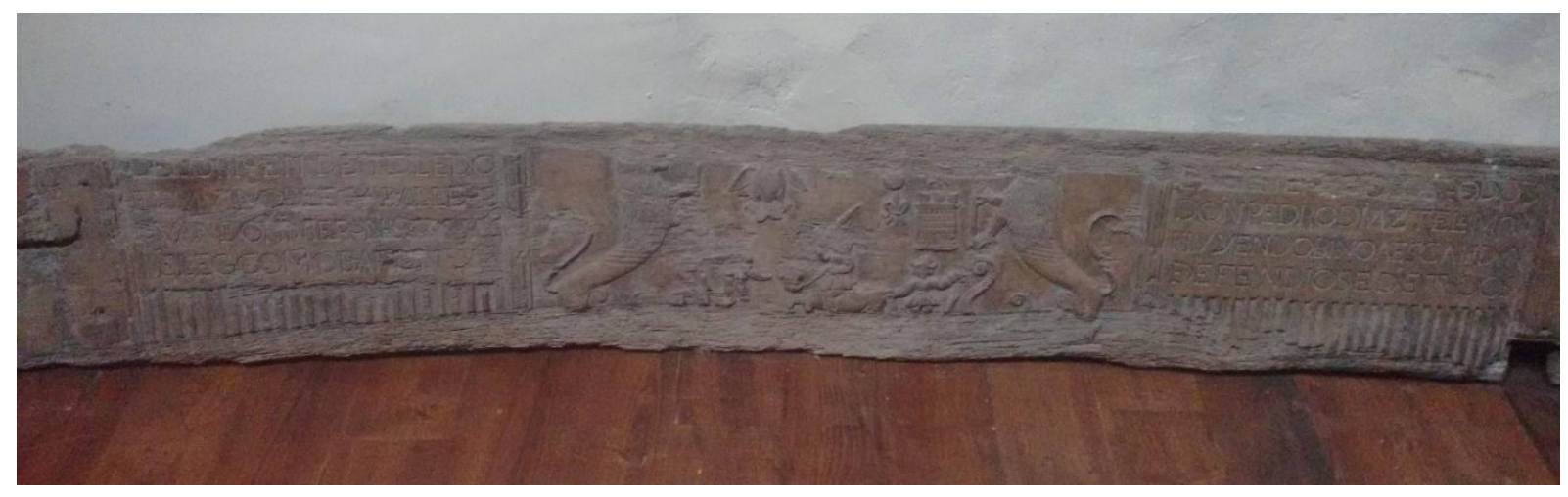

Fig. 4. Banco de Iglesia encontrado en la Capilla de Santo Toribio.

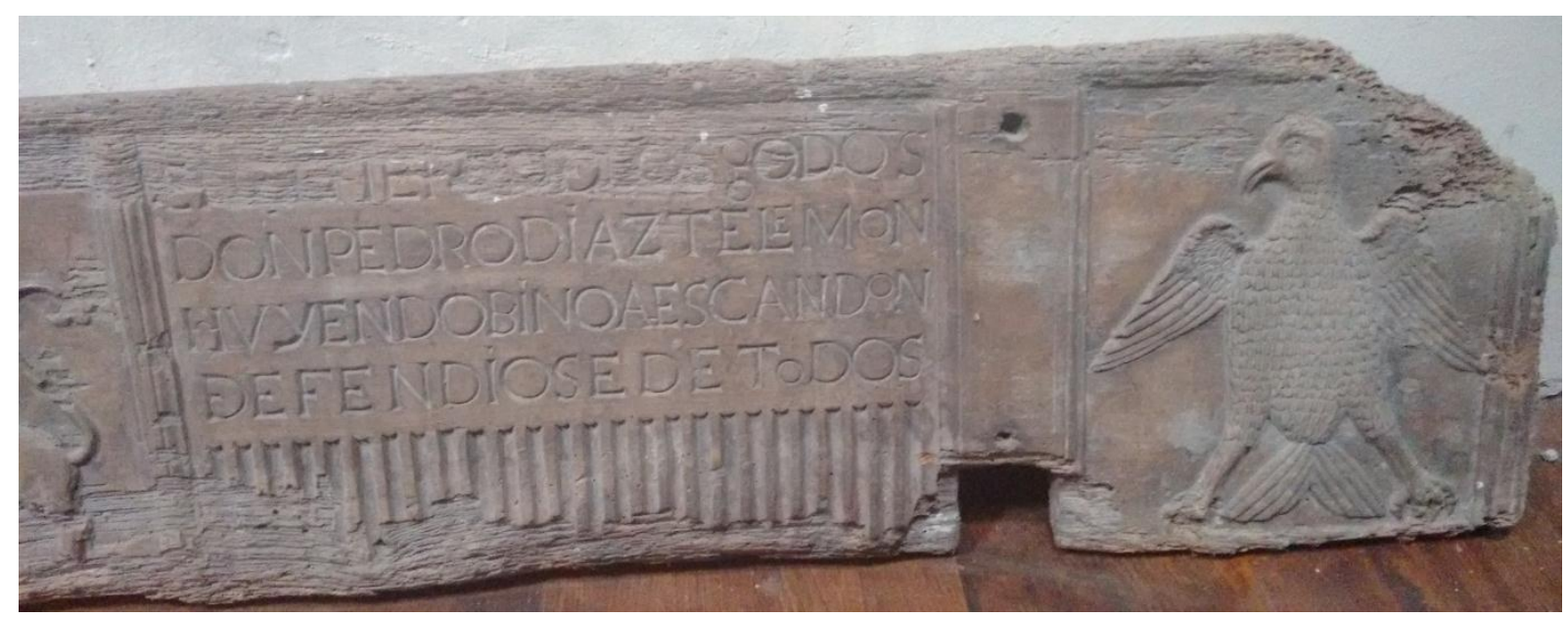

Fig. 5. Inscripción en el banco de iglesia. 


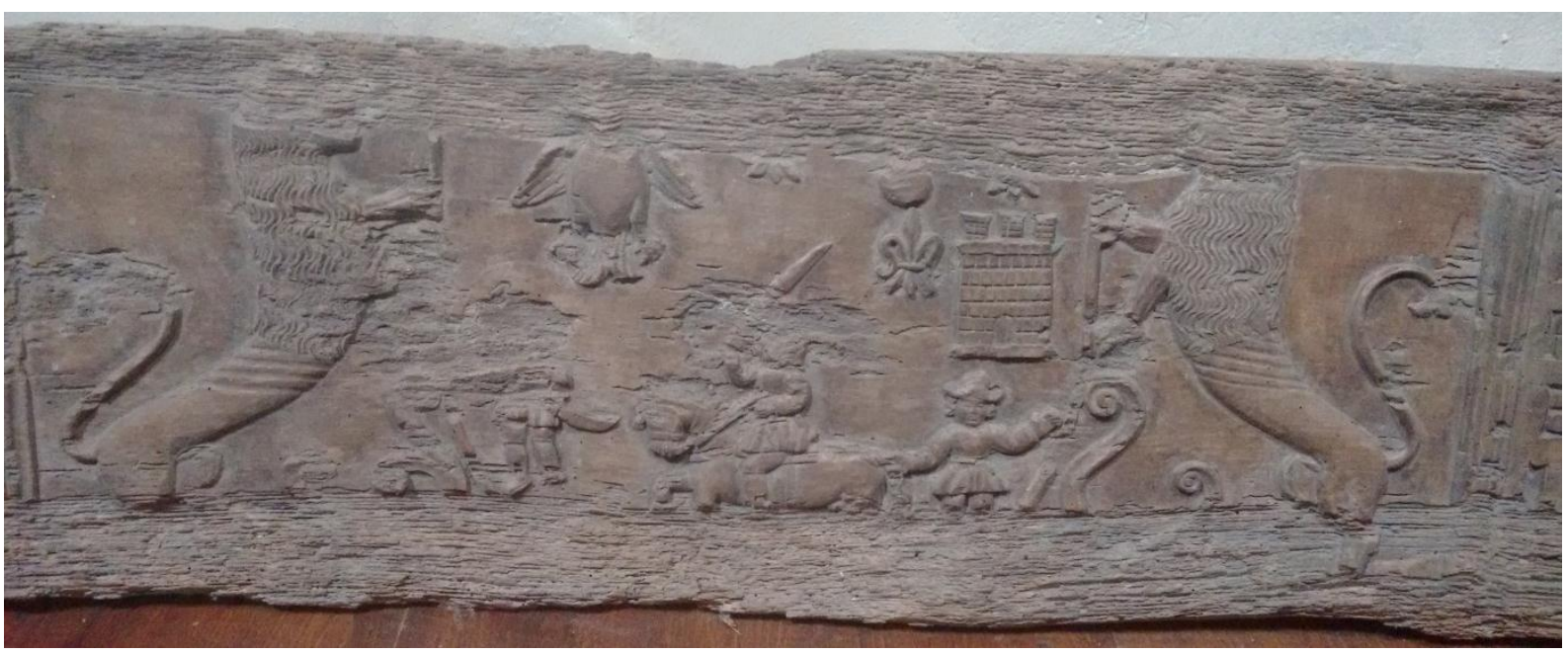

Fig. 6. Apellido Escandón en el panel central del banco.

Otro mueble que estaba presente era la mesa, cada una de diferente hechura ${ }^{54}$, de la que destacaremos la mesa redonda de "hechura francesa", que aludiría a una pieza procedente de un mercado exterior, en este caso francés, frente a un mobiliario casi en su totalidad proveniente de talleres locales, como en el caso de la silla anteriormente mencionada. También había dos bufetes con navetas y llaves ${ }^{55}$, que al igual que la mesa es un mueble de apoyo, y se usaría para estudiar, escribir, comer o para otros usos ${ }^{56}$. Hay constancia de que aún se conservaban dos mesas a comienzos de este siglo gracias a dos fotografías tomadas antes de su venta, en las que podemos observar que presentaban decoración tallada en los cajones (Fig. 7).

Finalmente haremos referencia a la cama que, según Nadal Iniesta, es el mueble de mayor significación e importancia dentro del ajuar doméstico a pesar de no ser el más abundante, debido al elevado precio que suelen alcanzar y por ser necesario contar con un mayor número de otras piezas ${ }^{57}$. En 1785 había doce lechos de cama de madera torneados ${ }^{58}$ y por lo tanto de cierta calidad. Además el número tan elevado nos dice que todos los miembros de la familia disponían de su propia cama para dormir, y esto no era corriente. Según Fernando Ramos Palencia, en relación a las familias palentinas y considerando su nivel de riqueza, se observa que de 1750 a 1850 sólo entre las familias con patrimonios superiores a los 50.000 reales había una correspondencia casi exacta entre el número de camas y el número de miembros de la economía familiar; incluso en la Europa preindustrial la familias o, por lo menos, muchos de sus miembros dormían en la sala o estancia principal, sobre paja o mantas que ponían cada noche en el suelo y guardaban a la mañana siguiente ${ }^{59}$. 


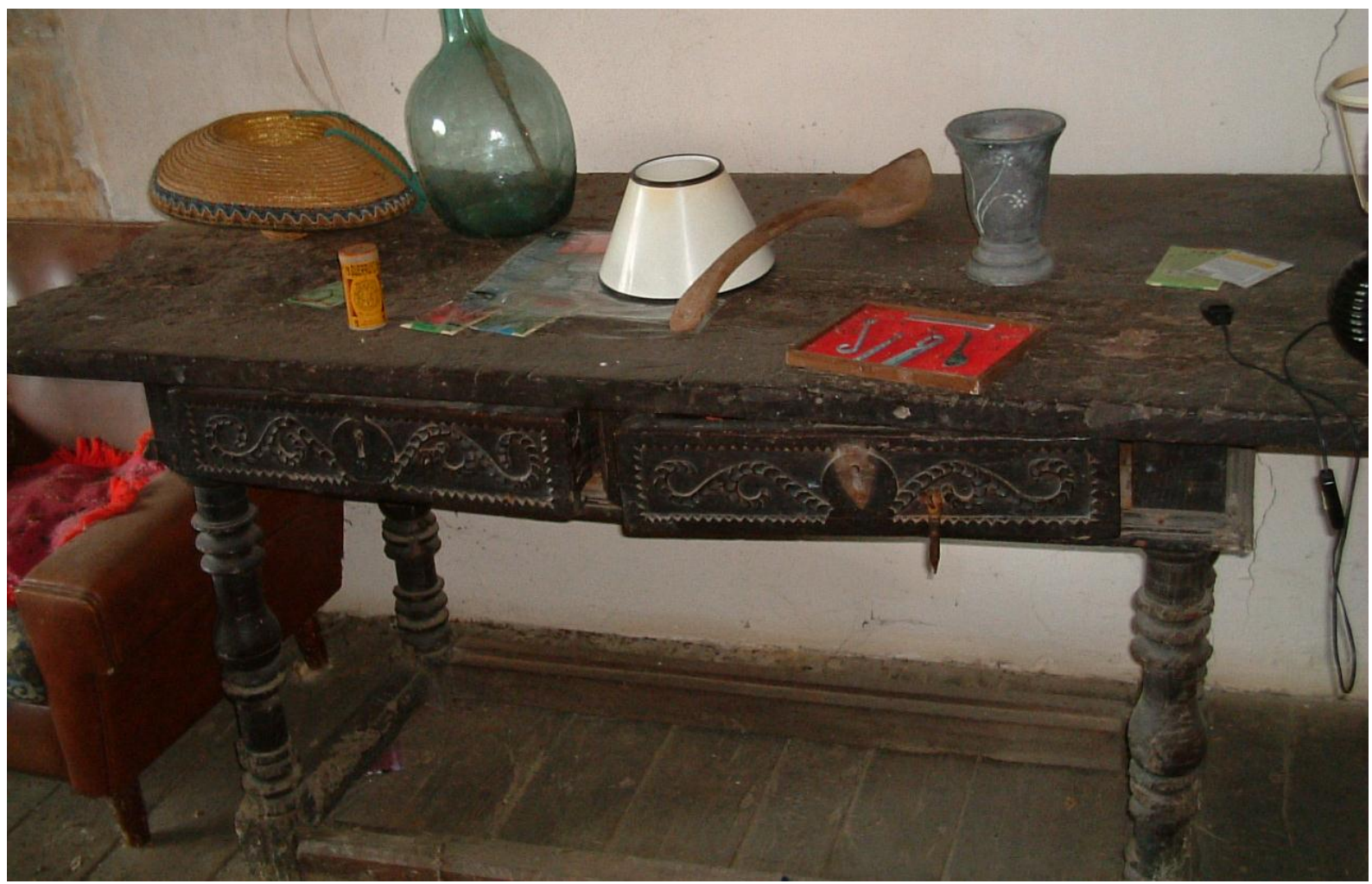

Fig. 7. Mesa inventariada antes de su venta

A parte del mobiliario también se inventariaba el ajuar doméstico y demás enseres de uso cotidiano y entre ellos estarían los utensilios de cocina. La cocina era la estancia donde tenía lugar la mayor parte de la vida doméstica; en ella se preparaba la comida, se conversaba y se reunía la familia al ser el lugar más cálido de la casa, ya que allí estaba el llar. La diferencia que podía haber entre una casa de campesinos y una casona, era la cantidad y calidad del ajuar, ya que los utensilios solían ser los mismos. Comparamos a continuación los utensilios disponibles en la casona ${ }^{60}$ con los que había en la casa de Juan Gómez de Prío en San Vicente de la Barquera ${ }^{61}$ en fechas muy próximas:

\begin{tabular}{|c|c|c|c|c|}
\hline UTENSILIOS & \multicolumn{2}{|c|}{$\begin{array}{l}\text { CASONA DEL COTERO } \\
1785\end{array}$} & \multicolumn{2}{|c|}{$\begin{array}{l}\text { CASA DE SAN VICENTE DE LA } \\
\text { BARQUERA } 1782\end{array}$} \\
\hline TIPO & CANTIDAD & MATERIAL & CANTIDAD & MATERIAL \\
\hline $\begin{array}{l}\text { asador } \\
\text { llares }\end{array}$ & 1 & hierro & 1 & hierro \\
\hline caldera & 2 & - & 2 & cobre (1), azófar (1) \\
\hline masera & 1 & - & & \\
\hline platos & 33 & $\begin{array}{l}\text { peltre (23), } \\
\text { madera (10) }\end{array}$ & 12 & Talavera(6), 6(peltre) \\
\hline escudillas & 36 & madera & 12 & - \\
\hline
\end{tabular}




\begin{tabular}{|l|l|l|l|l|}
\hline fuentes & 4 & $\begin{array}{l}\text { peltre (2), } \\
\text { madera (2) }\end{array}$ & - & - \\
\hline $\begin{array}{l}\text { medias } \\
\text { fuentes }\end{array}$ & 5 & $\begin{array}{l}\text { peltre (2), } \\
\text { madera (3) }\end{array}$ & - & - \\
\hline sartén & 1 & hierro & 1 & hierro \\
\hline cazo con & 1 & cobre & - & - \\
\hline $\begin{array}{l}\text { almirez } \\
\text { mano }\end{array}$ & - & - & - \\
\hline jarras & - & - & 6 & Talavera \\
\hline chocolateras & - & - & 2 & cobre (1), azófar (1) \\
\hline
\end{tabular}

Cuadro comparativo entre los enseres de cocina de la Casona de El Cotero en 1785 y la casa de Juan Gómez de Prío en San Vicente de la Barquera en 1782

Podemos comprobar que en su mayoría los utensilios son los mismos, salvo excepciones, y que lo que sí hay es una notable diferencia entre el número de platos y escudillas de una casa y de otra, que en la Casona de El Cotero vendría determinado por el número de miembros de la unidad familiar.

Además habría que mencionar aparte el menaje de plata, el cual ya no se encuentra en la cocina y que se asocia a la necesidad, por parte de los señores de la casa, de hacer ostentación, ya que no todo el mundo podía permitirse el lujo de tener cubiertos, platos y vasos de plata. En este caso, podría estar relacionado con el hecho de que Joseph Narciso había sido escribano y Administrador de las Rentas Reales, consideradas como categorías socioprofesionales de élite que solían contar con importantes menajes ${ }^{62}$.

\begin{tabular}{|lll|}
\hline MENAJE DE PLATA & & \\
UTENSILIOS & 1785 & 1797 \\
vasos & 6 & 8 (6 de encaje) \\
varquillos & 3 & - \\
pimentoneros & 2 & 2 \\
jícara de coco & 1 & - \\
servillas & 2 & 1 \\
cuchara & 10 & 11 \\
tenedor & 10 & 1 (antiguo) \\
cubiertos & - & 19 (sin especificar) \\
taza & - & 1 \\
\hline
\end{tabular}

Cuadro comparativo del menaje de plata en 1785 y 1797

Parece ser que en Palencia en 1830-1840 entre el $45 \%$ y el $60 \%$ de las familias poseían vasos, platos y cubiertos de plata, que era un cifra que doblaba a 
las de mediados del siglo XVIII. ${ }^{63}$ Según nos dice Sanz de la Higuera ${ }^{64}$, en el Burgos del siglo XVIII escaseaban los cuchillos, al igual que los platos de plata y peltre, que sólo estaban presentes en las casas de familias pertenecientes a las categorías socioprofesionales más aristocráticas. Podemos observar que en la casona tampoco disponían de cuchillos ni platos de plata, pero sí que contaban con vasos y otros cubiertos de plata además de numerosos platos de peltre.

Por otro lado, la ropa en el Antiguo Régimen, al ser considerada un símbolo de rango social, era un bien transmisible que debía pasar de una generación a otra o podía ser objeto de donaciones privadas, incluso entre señores y criados ${ }^{65}$. En 1785 se inventaría la ropa militar del difunto66: un capote, una capa, una chupa, una casaca, unos calzones de paño de Tarazona, un armador de "manfor" 67 azul, un sombrero y dos pañuelos de seda; sobre la demás ropa que pertenecería al difunto sólo sabemos que "aunque el difunto tenía y dejó más chupas y calzones ya andado, esto se dio al que le amortajó y de limosna"68, un ejemplo de esas donaciones que mencionamos anteriormente. En cambio en 1797 sí se inventaría la ropa de vestir de hombre 69 que podemos ver en el cuadro siguiente, de los cuales un calzón, un chupetín, una casaca y un capote pertenecían al vestido militar:

\begin{tabular}{|c|c|c|}
\hline PRENDA & NÚMERO & GÉNERO \\
\hline $\begin{array}{l}\text { ropa blanca (camisa y } \\
\text { calzoncillo) }\end{array}$ & 10 & - \\
\hline pares de calzones & 11 & pana (2), paño (4) \\
\hline pares de medias & 4 & lana \\
\hline chupa & 2 & pana (1), paño (1) \\
\hline casaca & 5 & paño (4),monfort (1) \\
\hline armadores & 2 & cotonia \\
\hline chaqueta & 1 & bayetón \\
\hline chalecos & 6 & bayetón (5), seda (1) \\
\hline capote & 1 & - \\
\hline ceñidores & 2 & estambre, seda \\
\hline redecilla & 1 & - \\
\hline sombreros & 3 & - \\
\hline pares de zapatos & 3 & - \\
\hline botines & 1 & paño \\
\hline
\end{tabular}

Prendas de ropa de vestir inventariadas en 1797

Como podemos observar nos encontramos ante un vestuario bastante amplio para hombre y de muy diferentes calidades, de la que podemos destacar la seda, incluso de algunas prendas disponían de varias mudas. Esto nos habla de un hombre bien vestido acorde a su puesto de trabajo. No hay ropa inventariada de mujer ni de niño, ya que sólo se inventariaron lo bienes libres del difunto. 
En cuanto a ropa para la casa o ropa blanca esta también es abundante en cuanto a tipos y materiales ${ }^{70}$.

\begin{tabular}{|c|c|c|c|c|}
\hline \multicolumn{5}{|l|}{ ROPA DE CASA } \\
\hline TIPO & 785 & TEJIDO & 797 & TEJIDO \\
\hline colchones & & lana & & - \\
\hline jergones & & lienzo & & - \\
\hline fundas & & lana & & - \\
\hline colchas & & $\begin{array}{l}\text { lana manchega } \\
\text { (varios colores) }\end{array}$ & & lana (2), algodón (2) \\
\hline cobertores & & $\begin{array}{ll}\text { lana } & \text { (varios } \\
\text { colores) }\end{array}$ & & lana (varios colores) \\
\hline sábanas & 4 & $\begin{array}{lr}\text { cerro } & (17), \\
\text { estopilla } & (4), \\
\text { encaje }(1) & \end{array}$ & 6 & $\begin{array}{l}\text { holanda (2), estopilla (2), } \\
\text { cerro y crea }(22)\end{array}$ \\
\hline mantel & & - & & 1 fino y 2 bastos \\
\hline almohadas & & - & & crea \\
\hline servilletas & & - & 6 & 12 finas y 4 bastas \\
\hline paños de mano & & - & & - \\
\hline peinadores & & - & & crea (1), holanda (1) \\
\hline
\end{tabular}

Cuadro de la ropa de casa inventariada en 1785 y 1797

En lo referente a textiles también se inventaría la ropa litúrgica, que sería utilizada por los miembros de la familia pertenecientes al clero para oficiar la misa en la Capilla de El Cotero. En 1785 había una casulla de Damasco, un alba de crea o Roan, un ámito, una estola y el manípulo ${ }^{71}$ y en 1797 a estos se añade un cíngulo, corporales, una palia y manteles de altar ${ }^{72}$.

Finalmente en estos inventarios se hace mención a ciertos objetos que podemos considerar de "lujo", ya que no estaban al alcance de todos, y son demostrativos de tener ciertas inquietudes estéticas. Nos referimos a las alhajas y otros objetos de adorno personal de plata, que suelen ser un indicativo por parte de estas familias de que, tras incrementar su poder adquisitivo y cubrir sus necesidades básicas, pueden permitirse el lujo de destinar parte de su dinero a esta clase de artículos ${ }^{73}$. Así en 1785 había ${ }^{74}$ : un reloj de campanilla y su caja, un bastón de junco con empuño de plata, dos moras doradas, dos campanillas de plata, una cadena de plata para colgar llaves y un cáliz con la patena, para la capilla éste último. En 1797 la cantidad de estos artículos de plata se ve incrementada ${ }^{75}$ : una hebilla para corbatín, unas hebillas para zapatos, dos campanillas para niños, una cruz de madera engarzada en plata, una cruz de plata sobredorada con crucifijo, una cinta plateada, dos pares de pendientes de 
plata, dos moras de plata sobredoradas, dos relicarios engarzados en plata, dos cajas de plata y una campanilla para la capilla.

Lo que resulta curioso es que no se haga mención a la tenencia de ningún tipo de libros, que normalmente responden a intereses intelectuales, aunque por ejemplo en Palencia a mediados del siglo XVIII solamente el 15\% de las familias poseían algún libro ${ }^{76}$. No obstante, no pensamos que se deba a la falta de interés ya que Joseph Narciso debía de ser un hombre culto de acuerdo a los oficios que desempeñaba. Es más, habiendo miembros del clero en la familia sería lógico que por lo menos hubiera algún libro de temática religiosa. Tampoco se inventarían pinturas ni estampas, que tal vez no fueran muy comunes en la decoración de las casas de la zona ya que por ejemplo, según $\mathrm{M}^{\mathrm{a}}$ Eugenia Escudero Sánchez ${ }^{77}$, pocas eran las casas de San Vicente de la Barquera que estaban decoradas con ellas y si las había eran poco numerosas. Sin embargo, según Máximo García Fernández, durante el siglo XVIII en Medina de Rioseco el 89\% de los habitantes poseía alguna pintura ${ }^{78}$.

\section{Conclusiones}

A tenor de los bienes inventariados en 1785 y 1797, y teniendo en cuenta que en inventario de 1797 sólo se da cuenta de los bienes libres, podemos concluir que la familia Guerra-Mier vivía con cierta comodidad y confort, aunque no contaran con el lujo del que sí disfrutarían las grandes familias residentes en las ciudades. Esta familia vivía en la zona rural, muy alejada de las grandes urbes, donde no se consideraría necesario demostrar tanta ostentación, siendo también complicado acceder a ciertos mercados como el de arte. No obstante, con toda probabilidad su nivel de vida sería superior al del resto de los vecinos.

El archivo de los Guerra está formado por más inventarios de los que aquí mencionamos, pero hemos centrado nuestro análisis en los que pertenecen al periodo del Antiguo Régimen, fechados en el siglo XVIII, aunque hagamos referencia a otros posteriores en los que se han hecho alusiones a muebles que se conservarían aún en el siglo XIX, pero que corresponderían casi con total seguridad al siglo anterior. Por lo que hemos podido observar, entre 1785 y 1797 ni la cantidad ni la variedad de muebles varió considerablemente, abundantes en ambos casos, teniendo en cuenta que en siglo XVIII pocas eran las casas que poseyeran más muebles que las típicas arcas, catres o escaños. Por ejemplo, no era común que las casas tuvieran un número tan elevado de camas como en esta, ya que lo normal era que si las había se compartieran entre los miembros de la familia. No es que estos inventarios ofrezcan una descripción excesivamente detallada del mobiliario pero sí dejan entrever que, al menos un determinado número de muebles, eran de buena calidad gracias al uso de maderas nobles y el trabajo de talla que presentaban algunos de ellos. Esto indica que no se trataba simplemente de muebles funcionales, además cumplían una función estética. También lo demuestra el hecho de contar con cubertería, vasos y vajilla de plata que utilizarían en momentos de reunión para hacer alarde y mostrar a los demás su capacidad económica. Las vestimentas y ropas de casa también son numerosas, algunas incluso de calidad superior. Aun así, sí que resulta extraño la 
falta de libros y cuadros, ya que al menos deberían contar con alguna lámina o libro de carácter religioso, que eran los más comunes en la época.

De todas formas, para ser capaces de hacernos una verdadera imagen del nivel de vida que llevarían realmente, sería necesario poder estudiar y analizar otros inventarios de otras familias de la zona, no sólo de su misma condición, sino de otras que tuvieran una mayor o menor capacidad económica, para de esta manera poder establecer unas conclusiones acerca de la cultura material en el oriente asturiano, su evolución y ponerla en relación con otros lugares, tanto a nivel regional como a nivel nacional.

\section{NOTAS}

${ }^{1}$ GONZALEZ HERAS, Natalia, "Vivienda e interiores domésticos en el Madrid Ilustrado" en Cultura material
y vida cotidiana moderna: escenarios, Madrid, Sílex ediciones S.L., 2013, p. 151.
${ }^{2}$ FRANCO RUBIO, Gloria, "La vivienda en el Antiguo Régimen. De espacio habitable a espacio social” en Chronica Nova, $\mathrm{n}^{\circ}$ 35, 2009, p. 91.

${ }^{3}$ NADAL INIESTA, Javier, "El mobiliario doméstico en la Murcia de principios del siglo XVIII (1700-1725), Imafronte, $\mathrm{n}^{\circ}$ 18, 2006, p. 93.

${ }^{4}$ En la actualidad la casona forma parte de un conjunto más amplio de edificaciones que se fue conformando a lo largo de los años. La corralada acoge además de la casona una capilla privada y otras dependencias de servicio como el silo, la hornera y las cuadras. La estructura actual de la casona responde a distintos momentos cronológicos constructivos. El bloque central correspondería al siglo XVII y aunque no podemos concluir que tuviera este aspecto desde su origen, presenta la típica fachada de casona montañesa -dos arcos de medio punto en el piso bajo, solana en el piso noble entre muros cortafuegos y desván en el piso superior- ; ya en el siglo XVIII se levantará el bloque izquierdo, al mismo tiempo que la capilla (fechada en 1771) y en el siglo XIX el bloque derecho. Merece ser destacada la talla decorativa de zapatas y pies derechos a base de motivos florales en la balconada, que de nuevo podemos apreciar en la decoración de la capilla.

${ }^{5}$ Se alude a él como "dueño y fundador de esta casa y de su vínculo" y de la capellanía de Santo Toribio en la Iglesia parroquial de San Andrés de Buelles y privilegio de la Casa de El Cotero.

${ }^{6}$ Testamento otorgado por Joseph Narciso Guerra de Mier en 1777, f. 27v, Protocolos Notariales, caja 115, Archivo Municipal de Llanes.

7 “ (...) Lizenciado Don ThoribioGonzález de Serdio, presvitero, manifiesta que quando se casó María González de Serdio, su hija natural con el zitado Alonso, la hizo donazión de las casas del Cotero Altas y vajas, tierras, prados y Árboles que tenía, detrás, adelante, al reededor de ella (...)" en el Pleito llevado a cabo entre Joseph Antonio y Antonio Joseph Guerra de Mier y los demás coherederos de Joseph Narciso Guerra de Mier y Doña $M^{a}$ Antonia Fernández de Serdio entre 1785 y 1799, f. 224r, Archivo particular.

${ }^{8}$ Era común que cuando se llevaba a cabo una obra importante en algún edificio se dejara constancia de ello por ejemplo, y como en este caso, colocando los escudos de armas si se trataba de una familia con linaje reconocido.

${ }^{9}$ TORAL Y FERNÁNDEZ DE PEÑARANDA, Enrique, "Los Mayorazgos no creaban nobleza pero contribuían a mantenerla" en Boletín del Instituto de Estudios Giennenses, nº 159, 1996, p. 23.

${ }^{10}$ Inventario de los bienes que quedaron por el fallecimiento de Joseph Narciso Guerra de Mier y Ma Antonia Fernández de Serdio en 1785, contenido en el Pleito llevado a cabo entre Joseph Antonio ... op. Cit. ff. 31v-32r y f. 220v.

${ }^{11}$ FAYA DÍAZ, Ma Ángeles, La nobleza en la Asturias del Antiguo Régimen, Oviedo, KRK Ediciones, 2004, p. 123.

12 “y también hube y heredé más considerable cantidad de vienes y dineros, Alhajas de plata, Ropa y otros efectos por el testamento y última disposición que otorgó y vajo de la qual falleción Don Joseph Antonio Guerra de Mier, mi tío (...) y vinculó en mí [.] los vienes que el referido Don Joseph Antonio thenía así en el citado lugar de Mier, como en otras partes, con ciento cincuenta onzas de plata labrada (...)" en Testamento otorgado por Joseph Narciso... cit. ff. 28v-29r 


\begin{abstract}
${ }^{13}$ Interrogatorio de 1749 del Catastro de Ensenada, ff. 459-460, en https://pares.mcu.es/catastro
${ }^{14}$ Inventario de los bienes que quedaron por ... cit. ff. 20r-47v.

15 “ (...) padres comunes hicieron considerables mejoras en los vienes vinculados, y tan grandes que comenzando por la casa en que vivían y era afecta al vínculo que posehía la difunta Doña María Antonia Fernández de Serdio, la reedificaron a toda costa haciéndola de nuevo, en tales términos, que de una casa muy regular, hicieron un palazio, cuyo valor excedía con el reedificio en cinco partes de seis al de la antigua y posteriormente después que se encendió la reparó el citado Don Joseph Narciso de modo que vale diez tantos más de lo que antiguamente valía, pues ascendió entonces su precio según regular cómputo al de seiscientos Ducados poco más o menos, vale en el día más de seis mill, y esto sin contar con la cozina que nuevamente se hizo y añadió a ella y vale no pequeña cantidad. (...) como también la capilla que de nueva planta hizo Don Joseph quando estaba viudo y que asciende indudablemente a más de treinta mill reales con inclusión de los ornamentos, vestiduras y demás con que se halla dotada para la celebrazión del santo sacrificio de la misa" en Pleito llevado a cabo entre Joseph Antonio y Antonio Joseph Guerra de Mier y los demás coherederos de Joseph Narciso Guerra de Mier y Doña $M^{a}$ Antonia Fernández de Serdio entre 1785 y 1799, op. cit.f. 220r
\end{abstract}

${ }^{16}$ Inventario de los bienes que quedaron por ... cit. f. $47 \mathrm{v}$

${ }^{17}$ SANZ DE LA HIGUERA, Francisco: "Familia, hogar y vivienda en Burgos a mediados del siglo XVIII. Entre cuatro paredes, compartiendo armarios, camas, mesas y manteles" en Investigaciones históricas: Época Moderna y contemporánea, $\mathrm{n}^{\mathrm{o}}$ 22, Valladolid, 2002, p. 201

${ }^{18}$ A excepción de su hermano Antonio Joseph, los demás coherederos querían declarar nulas las tasaciones de los bienes de la herencia y llevar a cabo una nueva tasación y división ya que, según ellos, se habían realizado con mucho retraso tras la muerte de su padre.

${ }^{19}$ Juez Noble de Peñamellera en 1825 y Alcalde Constitucional de Peñamellera entre 1844 y 1845 en Protocolos Notariales: cajas 285, 294 y 295, Archivo Municipal de Llanes.

${ }^{20}$ Fiscal de Panes en 1905, en El Eco de los Valles, Panes, 20 de Junio de 1905, s/p

${ }^{21}$ GARCÍA LÓPEZ, Ana Isabel: La arquitectura señorial en Peñamellera Baja. La Casona de los Guerra en El Cotero de Buelles, Trabajo de Investigación Tutorado, Universidad de Oviedo, 2010, p. 124

${ }^{22}$ PIERA, Mónica y MESTRES, Albert, El mueble en Cataluña: el espacio doméstico del Gótico al Modernismo, Colección Patrimoni Artístic de la Catalunya Central, Manresa, Fundació Caixa Manresa, Angle Editorial 1999, p. 19

${ }^{23}$ GARCÍA FERNÁNDEZ, Máximo, Herencia y patrimonio familiar en la Castilla del Antiguo Régimen (16501834). Efectos socioeconómicos de la muerte y la partición de bienes, Valladolid, Secretariado de Publicaciones, Universidad de Valladolid, 1995, p. 21

${ }^{24}$ GONZÁLEZ HERAS, Natalia, "Vivienda e interiores... cit. p. 156

${ }^{25}$ El problema con el inventario se produjo a raíz de la pretensión de algunos herederos de declarar nulas las tasaciones de los bienes de la herencia y llevar a cabo una nueva tasación y división ya que, según esto, el inventario se había realizado con mucho retraso tras la muerte de su padre.

${ }^{26}$ GARCÍA FERNÁNDEZ, Máximo, "Percepciones de la apariencia castellana dentro de España y en Roma. Imagen, cultura material y estilos de vida comparados a finales del Antiguo Régimen" en Cuadernos dieciochistas, Ediciones Universidad de Salamanca, 2008, p. 127

${ }^{27}$ HERNÁNDEZ LÓPEZ, Carmen: "Cultura material y especialización de la casa (Campo de Montiel 16501800)" en Apariencias contrastadas: contraste de apariencias. Cultura material y consumos del Antiguo Régimen, Universidad de León, 2012, p. 24

${ }^{28}$ GARCÍA FERNÁNDEZ, Máximo: "Percepciones de la apariencia castellana..." cit. p. 141

${ }^{29}$ LÓPEZ ÁLVAREZ, Juaco y GARCÍA GRAÑA, Armando, "El mobiliario en la casona asturiana" en Los asturianos: Raíces Culturales y sociales de una identidad, Oviedo, Editorial Prensa asturiana, 2004, p. 50

${ }^{30}$ Debemos tener en cuenta que los muebles al que hace referencia el inventario de 1797 son bienes libres, por lo que podría haber en la casona algún mueble más asociado a los bienes vinculados, como por ejemplo las arcas.

${ }^{31}$ Sólo se hace referencia a los muebles de herencia libre.

${ }^{32}$ Inventario de los bienes que quedaron... cit. f. $7 \mathrm{r}$

${ }^{33}$ Partición y división de bienes y herencia libre que quedó por defunción de Josef Antonio Guerra de Mier de 1831 , f. 13v, Archivo particular. 
${ }^{34}$ RAMOS PALENCIA, Fernando: Pautas de consumo y mercado en Castilla 1750-1850. Economía familiar en Palencia al final del Antiguo Régimen, Madrid, Sílex Universidad, 2010, p. 190

${ }^{35}$ DÍAZ QUIRÓS, Gerardo, "Mobiliario del siglo XVIII en Asturias" en El mueble del siglo XVIII: Nuevas aportaciones a su estudio, Associació per l'éstudi del moble, Institut de Cultura Disseny Hub Barcelona, Barcelona, Museo de les Arts Decoratives, Ajuntament de Barcelona, 2008, p. 106

${ }^{36}$ Inventario de los bienes que quedaron ... cit. ff. $7 \mathrm{r}-7 \mathrm{v}$

${ }^{37}$ Los bienes duraderos y semiduraderos se clasifican según su estado de conservación como nuevos, usados o viejos. RAMOS PALENCIA, Fernando, Pautas de consumo... cit. p. 51

${ }^{38}$ ESCUDERO SÁNCHEZ, M M Eugenia, “Obras de arte, objetos preciosos, libros y ajuar doméstico en algunas viviendas de los siglos XVII y XVIII de San Vicente de la Barquera” en Edades, Revista de Historia, 7 , Universidad de Cantabria, 2000, p. 52

${ }^{39}$ RAMOS PALENCIA, Fernando, Pautas de consumo... cit. 143

${ }^{40}$ AGUILÓ ALONSO, M ${ }^{\mathrm{a}}$ Paz, El mueble en España durante los siglos XVI y XVII, Madrid, Editorial de la Universidad Complutense, Servicio de reprografía, 1990, p. 465

${ }^{41}$ Copia del inventario hecho de los bienes... cit. f.7v

${ }^{42}$ Inventario de los bienes que quedaron ... cit. f. $7 \mathrm{v}$

${ }^{43}$ RAMOS PALENCIA, Fernando, Pautas de consumo... cit. p. 190

${ }^{44}$ Partida y liquidación de los bienes que quedaron por el fallecimiento de Pedro Antonio Guerra de Mier entre los herederos hecha en 1864, f. 2r, Archivo Particular

${ }^{45}$ Inventario de los bienes que quedaron ... cit. f.7v

${ }^{46}$ Copia del inventario de los bienes que quedaron ... cit. f. $7 \mathrm{v}$

${ }^{47}$ Inventario de los bienes que quedaron ... cit. f. $7 \mathrm{r}$

${ }^{48}$ Ibid...op. cit. f. $7 \mathrm{r}$

${ }^{49}$ GARCÍA LÓPEZ, Ana Isabel: La arquitectura señorial... cit. p. 101

${ }^{50}$ LÓPEZ ÁLVAREZ, Juaco y GARCÍA GRAÑA, Armando: “El mobiliario... cit. p. 50

${ }^{51}$ Esta inscripción aparece de nuevo en la Torre del Palacio de Don García de Noriega en Cimiano, datada en el siglo XVII, si bien no es igual literalmente ya que presenta alguna variación.

${ }^{52}$ Copia del inventario de los bienes que quedaron por ... cit. f. 20r-20v.

${ }^{53}$ En el panel central se dispone una escena con gran número de figuras y elementos: dos leones rampantes a los lados, un caballero montado en acto de descargar la espada sobre otra figura, sin cabeza debido al deterioro, que haría alusión al moro que se cita en la inscripción, ya que éste tiene una espada de filo curvado de origen árabe, y tras él un caballero y parte de un águila. Se trata de la misma representación que la del escudo de los Escandón situado en la solana. Flanquean el respaldo dos águilas de grandes dimensiones.

${ }^{54}$ Una mesa "rasa", dos mesas "con dos navetas cada una y sus llaves", dos mesitas pequeñas "rasas" y una mesa redonda de "hechura francesa" en el Inventario de los bienes que quedaron ... cit. f. 7r

${ }^{55}$ Inventario de los bienes que quedaron... cit. f. $7 \mathrm{r}$

${ }^{56}$ Diccionario de Autoridades, Tomo I, 1726, en www.rae.es,

${ }^{57}$ NADAL INIESTA, Javier, "El mobiliario doméstico en la Murcia..." cit. p. 96

${ }^{58}$ Son doce lechos de cama torneados "la una de hechura de media cama ya vieja y las otras usadas parte de ellas y camas enteras" en el Inventario de los Bienes que quedaron ... cit. f. 7v

${ }^{59}$ RAMOS PALENCIA, Fernando: Pautas de consumo ... cit. p. 141-142

${ }^{60}$ Inventario de los bienes que quedaron ... cit. f. $7 \mathrm{v}$

${ }^{61}$ Casa perteneciente a Juan Andrés Gómez del Prío, administrador de la real venta de tabaco de la Villa de San Vicente, según el estudio de ESCUDERO SÁNCHEZ, Ma Eugenia, “Obras de arte, objetos preciosos... cit. p. 57

${ }^{62}$ SANZ DE LA HIGUERA, Francisco José, “Aproximación a la mesa de los burgaleses. Cuberterías y platos en el setecientos" en Cultura material y vida..., , p. 187

${ }^{63}$ RAMOS PALENCIA, Fernando: Pautas de consumo... cit. p. 152

${ }^{64}$ SANZ DE LA HIGUERA, Francisco José, “Aproximación a la mesa... cit. p. 190

${ }^{65}$ ORDURA PORTÚS, Pablo, “Aspectos de la cultura material de la nobleza del Ebro durante el Antiguo Régimen” en Red Cultural, Brocar 32, 2008, p. 97 


\footnotetext{
${ }^{66}$ Inventario de los bienes que quedaron... cit. $7 \mathrm{v}$

${ }^{67}$ Se referiría a que procedería de Monfort (ciudad de Francia).

${ }^{68}$ Inventario de los bienes que quedaron... cit. f. $7 \mathrm{v}$

${ }^{69}$ Copia del inventario de los bienes que quedaron ... cit. $8 \mathrm{r}$

${ }^{70}$ Inventario de los bienes que quedaron... cit. ff- 7v-8r y Copia del inventario de los bienes que quedaron... cit. ff. $8 \mathrm{v}-9 \mathrm{r}$

${ }^{71}$ Inventario de los bienes que quedaron... cit. f. 9r

${ }^{72}$ Copia del inventario de los bienes que quedaron... cit. ff. $27 \mathrm{r}-27 \mathrm{v}$

73 ALONSO ARISTIZABAL, Juan Luis, "Mobiliario y bienes muebles de dos familias hidalgas en la Asturias del Antiguo Régimen”, en Res Mobilis, vol. 3, no 3, 2014, p. 115

${ }^{74}$ Inventario de los bienes que quedaron... cit. f.7r-8r

${ }^{75}$ Copia del inventario de los bienes que quedaron ... cit. ff. $7 \mathrm{v}-8 \mathrm{r}$

${ }^{76}$ GARCÍA FERNÁNDEZ, Máximo, "El patrimonio doméstico y su simbología. La cultura popular castellana a través del ajuar mobiliario del hogar durante el Antiguo Régimen” en Historia de la propiedad. Patrimonio cultural. III Encuentro Interdisciplinar, Salamanca, 28-31 de Mayo de 2002, Madrid, Servicio de Estudios del Colegio de Registradores, 2003, p. 92

${ }^{77}$ ESCUDERO SÁNCHEZ, M ${ }^{\text {a }}$ Eugenia, “Obras de arte, objetos preciosos...” cit. p. 53

${ }^{78}$ GARCÍA FERNÁNDEZ, Máximo, "El patrimonio doméstico...” cit. p. 94
} 